\title{
1 Immune stimulation alters chemical profiles of adult Tribolium castaneum
}

2

3 Lai Ka LO ${ }^{1 \#}$, Reshma R ${ }^{1 \#}$, Lisa Johanna TEWES ${ }^{2 \#}$, Barbara MILUTINOVIĆ ${ }^{1}$, Caroline

$4 \quad$ MÜLLER $^{2}$, Joachim KURTZ ${ }^{1 *}$

5

$6{ }^{1}$ Institute for Evolution and Biodiversity, University of Münster, Hüfferstr. 1, 48149 Münster,

7 Germany

$8{ }^{2}$ Department of Chemical Ecology, Bielefeld University, Universitätsstr. 25, 33615 Bielefeld,

9 Germany

10

11 \# These authors contributed equally

12 *Corresponding author: joachim.kurtz@uni-muenster.de 


\section{Abstract}

Rapid recognition of disease cues is essential for preventing pathogenic infections and for disease management in group-living animals. Healthy individuals across taxa can detect illness in other conspecifics and adjust their responses to limit further infections of themselves and the group. However, little is known about potential changes in chemical phenotypes due to disease, which may mediate these responses. We here asked whether individual immune experience resulting from wounding or the injection of heat-killed bacteria of Bacillus thuringiensis (i.e., immune priming) leads to changes in the chemical profiles of adult red flour beetles (Tribolium castaneum). This group-living insect species is a well-studied example for both immune priming as a form of innate immune memory and niche construction via 'external immunity', i.e., the secretion of quinone-containing antimicrobials into the flour. Upon interaction with wounded conspecifics, naive beetles were previously found to not only up-regulate immunity, but moreover reduce gene expression of the evolutionary capacitor HSP90, an effect that has the potential to enhance adaptability. We here used gas chromatography-flame-ionisation detection (GC-FID) to study the composition of stink gland secretions and cuticular hydrocarbons (CHCs) of immune-primed and wounded beetles compared to controls. The overall profiles as well as target compounds of the stink gland secretions showed transient, slight changes after these treatments, particularly in wounded females. Priming and wounding led to pronounced changes in $\mathrm{CHC}$ profiles with increases in the proportion of methyl-branched alkanes. Furthermore, we found sex-specific differences, that were particularly pronounced in the CHCs, although the changes due to immune stimulation were overall similar in both sexes. We suggest that CHCs are potential candidates for the transfer of information related to individual immunological experience into the group. 
bioRxiv preprint doi: https://doi.org/10.1101/2021.03.23.436617; this version posted March 23, 2021. The copyright holder for this preprint (which was not certified by peer review) is the author/funder. All rights reserved. No reuse allowed without permission.

\section{Keywords}

40 immune priming, innate immunity, disease cues, cuticular hydrocarbons, GC-FID, niche

41 construction, stink glands, Tribolium castaneum, Bacillus thuringiensis 


\section{Introduction}

The ability to recognise the health-status of others is vital for decision making and the success of individuals. This is especially true in animal groups where increased contacts and host density facilitate the spread of diseases (Kappeler et al., 2015). Healthy individuals in many species were shown to modulate their behaviour and physiology in response to disease (Lopes, 2020), by either avoiding harmful microbes and diseased individuals (Arakawa et al., 2011; Schulenburg \& Ewbank, 2007; Stensmyr et al., 2012) or managing active infections once the pathogen had entered the group. The best-studied examples are found in eusocial insects (Cremer et al., 2018) that show remarkable group-level disease defences such as social distancing (Stockmaier et al., 2021), hygiene and sanitary care (Konrad et al., 2012;

Rosengaus et al., 1998) or social immunisation (Masri \& Cremer, 2014). However, still very little is known about the effects of immune status on chemical phenotypes which may mediate these responses.

Importantly, to enable individuals to respond to pathogenic threats and to adjust their reactions, they need to be able to detect disease cues in others. Chemical cues have been shown to allow healthy animals to identify diseased conspecifics across taxa (Behringer et al., 2020; Csata et al., 2017; Lopes, 2020; Pull et al., 2018). For example, eusocial insects can detect immunological and disease cues of other nestmates and adjust subsequent social responses towards diseased members (Pull et al., 2018; Sun et al., 2017). In honey bees, these responses lead to the modulation of social interactions among workers (Baracchi et al., 2012; Mondet et al., 2021; Richard et al., 2008) as well as immune activation in queens (Hernández López et al., 2017). Many of these reactions were shown to be mediated, among other compounds, by changes in cuticular hydrocarbon profiles (CHCs). CHCs are present on the surface of insects and consist of complex mixtures of straight-chain, methyl-branched, and unsaturated hydrocarbons (Blomquist \& Ginzel, 2021). Their content and composition can vary with age, diet, development stage, sex, temperature, and geographic origin of species or 
populations (Blomquist \& Bagnères, 2010). They are involved in a wide range of functions from prevention of desiccation to serving as pheromones or allelochemicals for recognition of species, sex, mutualistic partners, or hosts (Blomquist \& Bagnères, 2010; Howard \& Blomquist, 2005). CHCs are particularly important in social insects, where they serve for nestmate recognition and many aspects of regulation of the social interactions inside the nests (Leonhardt et al., 2016). Since CHCs are hardly volatile, direct contact is required for recognition of these compounds. In honey bees, immune challenge and wounding lead to changes in $\mathrm{CHC}$ profiles in workers, which are then likely recognised by queens upon contact and may result in the immune activation described above (Hernández López et al., 2017). Currently, similar observations are rare in non-social organisms (Gallagher et al., 2018), making it difficult to compare chemical disease communication across animal groups. We have previously shown in the red flour beetle, Tribolium castaneum (Coleoptera: Tenebrionidae), which is a non-social, but group-living (gregarious) insect species that lives in and consumes flour, that the interaction of naïve focal beetles with wounded conspecifics induced increased activity of the important immune effector phenoloxidase (PO) (Peuß et al., 2015). In addition to this social transfer of immunity, we also found a consistent reduction in expression of two genes coding for the heat shock protein HSP90, namely Hsp83 and Hsp 90 , in focal beetles. As the molecular chaperone HSP90 serves as an evolutionary capacitor (Rutherford \& Lindquist, 1998), such down-regulation has the potential to lead to increased adaptability via the release of cryptic genetic variation. However, it is up to now unknown, which cues emitted by wounded beetles could be recognised by the naïve focal beetles. Immune priming is a form of innate immune memory in invertebrates (Little \& Kraaijeveld, 2004; Milutinović \& Kurtz, 2016; Netea et al., 2016; Pham et al., 2007). Tribolium castaneum is a prime example for immune priming, which can be specific for the type of pathogen (Roth et al., 2009) and can be transferred from parents to offspring (Roth et al., 2010). In addition to protection achieved by their internal immune system, T. castaneum 
engages in external immune defences (Joop et al., 2014; Otti et al., 2014), i.e., a process of niche construction (Odling-Smee et al., 2013) mediated by the beetles' stink gland secretions (Sokoloff, 1974). These secretions serve a hygienic function, as they contain the benzoquinones ethyl- and methyl-1,4-benzoquinone (EBQ and MBQ) along with further substances with inhibitory effects on microbes (Li et al., 2013; Yezerski et al., 2007). However, at high concentrations these compounds become harmful to the beetles themselves (Sokoloff, 1974), and might also be involved in female density-dependent competition (Khan et al., 2018). Moreover, biosynthesis of the quinones depends on the availability of tyrosine, a semi-essential amino acid, which is also a substrate for the PO enzyme that is central to internal immune defences of crustaceans and insects (Cerenius et al., 2008). The amount of secretion might therefore be optimised by evolution (Joop et al., 2014) and adjusted to external conditions (Pedrini et al., 2010). In theory, the level or composition of the beetles' secretions inside the flour could be recognised by conspecifics and used for a potential adjustment of production and release of own secretions (Gokhale et al., 2017).

We here examined the influence of individual immune experiences, i.e., wounding and immune priming, compared to controls on the chemical profiles of red flour beetles, particularly with respect to stink gland secretions and CHCs. As a response to wounding and/or priming being a cue for a potential pathogenic threat, we expected to see (1) changes in the profile of the stink gland secretions and in the main compounds, EBQ, MBQ and their carrier 1-pentadecene (Loconti \& Roth, 1953; Villaverde et al., 2007); (2) changes in the CHC profiles, which may act as a cue for conspecifics, leading to the previously described changes in immunity and $H s p 83 / H s p 90$ expression . For the former, either higher or lower concentrations could be expected in response to wounding or priming, as an increased contribution to external immunity, or as a result of the trade-off with internal immunity responding to the wounding or priming, respectively. We analysed the chemical profiles for 
119 males and females separately, thereby taking into account potential sex differences in CHC

120 profiles and sex-specific functions of the secretions (Khan et al., 2018). 


\section{Methods}

3.1 Model organisms

Our study was done on the outbred strain Croatia 1 (CRO1) of T. castaneum, which was derived from a wild population originally collected in Croatia, May 2010 (Milutinović et al., 2013). This outbred population was then kept at $30^{\circ} \mathrm{C}, 70 \%$ humidity and a $12 \mathrm{~h}: 12 \mathrm{~h}$ light:dark cycle, in plastic boxes containing heat-sterilised $\left(75^{\circ} \mathrm{C}\right.$ for at least 24 hours) organic wheat flour (Bio Weizenmehl Type 550, dm-drogerie markt) with 5\% brewer's yeast powder (hereafter the flour-yeast mixture is referred to as "flour"). For this experiment, around 2,000 one month old adult beetles were allowed to mate and oviposit for $24 \mathrm{~h}$ in approximately $350 \mathrm{~g}$ flour. Following that, adult beetles were separated from the flour containing eggs using a $710 \mu \mathrm{m}$ mesh size sieve (Retsch). All beetles were kept individually to minimise any injuries due to conspecific cannibalism or mating (Alabi et al., 2008; Park et al., 1965; Via, 1999).

Bacillus thuringiensis morrisoni bv. tenebrionis (Btt) was obtained from Bacillus Genetic Stock Center (Ohio State University, USA) and heat-killed vegetative cells used for the priming treatment were prepared as previously described (Ferro et al., 2017; Roth et al., 2009). In short, $100 \mu \mathrm{L}$ of a $\mathrm{Btt}$ freezer stock (stored at $-80^{\circ} \mathrm{C}$ ) was inoculated into a $500 \mathrm{~mL}$ baffled flask containing $50 \mathrm{~mL}$ Luria Broth (Carl Roth $\mathrm{GmbH}+\mathrm{Co} . \mathrm{KG})$ and the culture was incubated at $30^{\circ} \mathrm{C}, 200 \mathrm{rpm}$ for $15 \mathrm{~h}$ in dark. Subsequently, the culture was transferred into a $50 \mathrm{~mL}$ Falcon conical tube and centrifuged at $3,645 \times \mathrm{g}$ at $4{ }^{\circ} \mathrm{C}$ for $10 \mathrm{~min}$. The bacterial pellet was washed once with phosphate buffered saline (PBS, Calbiochem $\left.{ }^{\circledR}\right)$ and the concentration adjusted to $1 \times 10^{9}$ cells $\mathrm{mL}^{-1}$. PBS (as injection/wounding control) and Btt at 1 $\times 10^{9}$ cells $\mathrm{mL}^{-1}$ solution (priming solution) were heated at $95{ }^{\circ} \mathrm{C}$ for $30 \mathrm{~min}$ to heat-kill the bacteria. All procedures were carried out under a horizontal laminar air-flow hood to keep the conditions sterile. 


\subsection{Immune treatment}

Ten days after oviposition, all experimental beetles were individually placed into sterile 96-well plates (Type F, SARSTEDT) containing $0.08 \mathrm{~g}$ flour per well. One week post eclosion, virgin beetles of both sexes were divided into three treatment groups, i.e. naïve (handling control), wounded (injected with sterile PBS) and primed (injected with heat-killed $B t t$ ). $18.4 \mathrm{~nL}$ (approximately 20,000 cells per injection in the priming treatment) of solution was injected with a nanoinjector (Drummond Nanoject II) into the dorsal vessel of adult beetles by puncturing the epidermis between the head and pronotum laterally towards the abdomen.

For preparation of stink gland secretion collection, 48 beetles of each sex underwent either of the three treatments (naïve, wounded and primed) and were sampled twice, after $24 \mathrm{~h}$ and $72 \mathrm{~h}$, resulting in $\mathrm{n}=8$ samples of individual beetles per sex, treatment and time point. Handling stress during the injection process can trigger the release of stink gland contents (Lai Ka Lo's personal observation). Therefore, sampling time points of $24 \mathrm{~h}$ and $72 \mathrm{~h}$ post treatment were chosen to allow the stink gland contents to replenish. After the treatment, beetles for sampling after $24 \mathrm{~h}$ were transferred into clean 96 -well plates for starvation to reduce the contamination of samples by faecal material and flour. Beetles to be sampled after $72 \mathrm{~h}$ received flour in well-plates until $24 \mathrm{~h}$ before extraction.

For preparation of profiling of $\mathrm{CHCs}, 72$ beetles of each sex underwent either of the three treatments, resulting in $n=6$ samples per sex and treatment with four beetles pooled into each sample. The time point of the sampling was chosen to be $18 \mathrm{~h}$ based on a previous study on T. castaneum (Peuß et al., 2015) that reported transfer of immunity, as well as a downregulation of the evolutionary capacitor Hsp90, both of which were mediated by social cues from conspecifics. This downregulation was strongest at the $18 \mathrm{~h}$ time point. After treatment, beetles were transferred into clean 96-well plates for starvation for $18 \mathrm{~h}$ until sampling. 
3.3 Extraction of beetle chemicals

For extraction of glandular secretions, beetles were transferred to individual $1.5-\mathrm{mL}$

safe-lock tubes (Eppendorf). These were immersed in ice water at $3{ }^{\circ} \mathrm{C}$ for $3 \mathrm{~min}$ to stimulate

the release of stink gland secretions (Joop et al., 2014) and then transferred to a $-20{ }^{\circ} \mathrm{C}$ freezer

to kill the beetles. $65 \mu \mathrm{L}$ ice-cold acetone (LC-MS grade, Sigma-Aldrich) containing $0.05 \mathrm{mg}$

$\mathrm{mL}^{-1}$ octadecane $(98.5 \%$, Sigma-Aldrich) as an internal standard was added to each frozen

comfort, Eppendorf) to extract the quinone-rich stink gland secretions. The extracts were

centrifuged for $5 \mathrm{~min}$ at $16,100 \times \mathrm{g}$ at $5^{\circ} \mathrm{C}$. Subsequently, $50 \mu \mathrm{L}$ of each extract was

transferred into brown vials (FisherBrand, Fisher Scientific) and kept at $-20^{\circ} \mathrm{C}$ until analysis.

Together with the beetle samples, four blank samples per time point were prepared that

underwent the whole extraction process but did not contain beetles.

killed at $-20^{\circ} \mathrm{C}$. The dead beetles were transferred to new $1.5-\mathrm{mL}$ tubes to exclude eventually released stink gland secretions stuck to the tube surface. To each sample, $120 \mu \mathrm{L}$ of $n$-hexane

containing the surface extracts were transferred to fresh $1.5 \mathrm{~mL}$ tubes without touching the 
beetle samples, four blank samples were prepared that underwent the whole extraction process but did not contain beetles.

\subsection{Chemical analysis, data pre-processing and feature identification}

All samples were analysed on a gas-chromatograph coupled with a flame ionisation detector (GC-2010 Plus, Shimadzu) and equipped with a VF-5ms column $(30 \mathrm{~m} \times 0.25 \mathrm{~mm} \times$ $0.25 \mu \mathrm{m}$, with $10 \mathrm{~m}$ EZ-guard column, J\&W Agilent Technologies) and an autosampler (AOC-20i, Shimadzu). For the analysis of stink gland secretions, a sample volume of $1 \mu \mathrm{L}$ was injected with a split ratio of 3 at a constant stream of hydrogen flow of $1.13 \mathrm{~mL} \mathrm{~min}{ }^{-1}$. The column oven temperature was set at $50{ }^{\circ} \mathrm{C}$, held for 2 minutes and increased to $300{ }^{\circ} \mathrm{C}$ with a rate of $10^{\circ} \mathrm{C} \mathrm{min}-1$, followed by a holding time of $10 \mathrm{~min}$. For the analysis of CHCs, 1 $\mu \mathrm{L}$ from each sample was injected with a split ratio of 2 at a constant nitrogen flow of 1.02 $\mathrm{mL} \min ^{-1}$. The column oven temperature started at $100{ }^{\circ} \mathrm{C}$, first increased to $230{ }^{\circ} \mathrm{C}$ with a rate of $20^{\circ} \mathrm{C} \mathrm{min}-1$, then increased to $260{ }^{\circ} \mathrm{C}$ with a rate of $5{ }^{\circ} \mathrm{C} \mathrm{min}^{-1}$, further increased to $277^{\circ} \mathrm{C}$ with a rate of $1^{\circ} \mathrm{C} \mathrm{min}-1$, and finally increased to $320^{\circ} \mathrm{C}$ with a rate of $5^{\circ} \mathrm{C} \mathrm{min}^{-1}$, which was held for 9.9 min. Additionally to the samples and blanks, two alkane mix standards, C8-20 and C8-C40 (both Sigma-Aldrich), were analysed using both chromatographic methods. Furthermore, commercially available standards of MBQ (98\% purity), methyl-1,4-hydroquinone (99\%, both Sigma-Aldrich) and ethyl-1,4-hydroquinone (97\%, Abcr) were analysed using the method for stink gland secretions. Data pre-processing was done using the GCsolution Postrun software (Version 2.30.00, Shimadzu), exporting peak areas with at least 5 (stink gland secretion) and 100 counts (CHCs), respectively. Retention time alignment of peaks was done in $\mathrm{R}$ (version 4.0.3, R Core Team, 2020) using the package GCalignR (Ottensmann et al., 2018), allowing a maximum shift in retention time by $0.05 \mathrm{~min}$. Features that could not be distinguished from those occurring also in blank samples were excluded. The resulting datasets were both 
normalised to the internal standard and only features detected in at least half of the replicates per treatment and sex (and time point in case of stink gland secretions) were considered for further analysis. In both datasets, relative values were calculated by expressing the amount of a certain feature as the proportion of the total amount of features considered for a sample. For feature identification, the retention times of peaks from the alkane mix standards were used to calculate the retention index (RI) of detected features according to Kováts (1958). From the stink gland analysis, benzoquinones (BQs) as well as other major compounds previously described in T. castaneum glandular secretions were identified by comparing their RIs to previous studies (Lehmann, 2015; Li et al., 2013), and by comparisons to the commercial standards analysed. Putative identification of $\mathrm{CHCs}$ was done by comparing the RIs with those published in studies by Alnajim et al. (2019), Awater-Salendo et al. (2020) and Lockey (1978).

\subsection{Statistical analyses}

All statistical analyses were done using R (version 4.0.3, R Core Team, 2020). To visualise dissimilarities between samples of naïve, wounded and primed beetles, non-metric multidimensional scaling (NMDS) was applied to all datasets using the metaMDS function in the package vegan (version 2.5-7, Oksanen et al., 2020). For this, datasets were transformed using the Wisconsin double standardisation (package vegan) of the square root values and pairwise dissimilarities were calculated based on the Kulczynski index. NMDS analysis was done on relative feature abundances, separately for the two time points for the analysis of stink gland secretions, and in all cases performed with both sexes included and also for both sexes separately. For the CHC profiles, naïve males and females were also compared in a separate analysis to visualise general $\mathrm{CHC}$ profile differences attributed to sex. Additionally to NMDS, permutational multivariate analysis of variance (PERMANOVA) was performed using the adonis function (package vegan) to test for the influence of treatment, sex and the 
interaction of these factors (only in cases were both sexes were included) on the dissimilarities displayed by the datasets. The same transformations and dissimilarity indices as for NMDS were employed and 10,000 permutations were used. Prior to the PERMANOVA, the betadisper and permutest (10,000 permutations) functions (package vegan) were used to confirm the homogeneity of the multivariate variance spread among the treatment groups. If significant treatment effects were found in the PERMANOVA analyses of CHCs of females and males separately, the pairwiseAdonis function (Martinez Arbizu, 2020) was used for post hoc tests with correction of p-values due to multiple comparisons between treatment groups using the Benjamini-Hochberg (Benjamini \& Hochberg, 1995) procedure $(\mathrm{a}=0.05)$.

For the secretions, we first identified features that differed between treatments using a conditional random forest classification $($ seed $245, \mathrm{n}$ trees $=500, \mathrm{n}$ variables per split $=5)(\mathrm{De}$ Moraes et al., 2014; Strobl, Hothorn, et al., 2009; Strobl, Malley, et al., 2009). The analysis was done on relative feature amounts, since it is difficult to control random gland emptying before and during experimental procedures and hence total amount of secretions may differ between animals for reasons other than experimental treatments. Random forest identified one peak as important for each sex, whose relative concentrations were further analysed in post hoc testing. For this, we also included target compounds with known biological activity EBQ, MBQ and 1-pentadecene (1-C15-ene) - and tested for the significance of our two main effects, 'treatment' (naive, wounded, primed) and 'sex' (male, female), as well as their interaction by fitting linear models (LM) using the $l m$ function from the base package in $\mathrm{R}(\mathrm{R}$ Core Team, 2018). Additionally, for the target features we analysed the absolute values as well, since those features were most abundant. We tested for data normality, heteroscedasticity, presence of multicollinearity and influential cases and obtained diagnostics plots (Q-Q plots and histograms of model residuals distribution and a plot to estimate nonlinear patterns of residuals). For all models, we first tested the significance of the overall 
model including the main effects and their interaction compared to a null model (intercept only) using anova function in R. If the model assumptions were not met, we first tried transforming the data using the package bestNormalize (Peterson, 2017), after which a nonparametric Kruskal-Wallis (KW) and post hoc comparisons were performed. Multiple comparison corrections were performed for the overall models (or KW tests) separately within absolute and relative datasets and for post hoc tests for each feature, using the Benjamini-Hochberg procedure $(\mathrm{a}=0.05)$. fold change values were calculated for all CHCs and replicates in comparison to the median value of the naïve male and female beetles and plotted as heatmaps using the package pheatmap (Kolde, 2019). Also, heatmaps comparing CHCs of naïve females and naïve males were generated based on z-scores for each CHC. All heatmap plots included Euclidean cluster analysis of CHCs. 


\section{Results}

291

292

\subsection{Stink gland secretions}

In the dataset acquired $24 \mathrm{~h}$ after treatment, 26 features were included, of which 24 were also considered in the dataset acquired $72 \mathrm{~h}$ after treatment (Table S1). The seven most dominant features could be identified by comparison of the RI to the literature and to commercial standards. The two benzoquinones, MBQ and EBQ, could clearly be identified, but the corresponding hydroquinones were not present in the dataset. The other five identified features were alkenes with one or two double bonds, namely 1,6-C15-diene, 1-C15-ene, 1C16-ene, 1,8-C17-diene and 1-C17-ene (Table S1).

The NMDS plots on relative features of this dataset showed only a slight separation of secretion composition between sex and treatment groups (Fig. 1a), which nevertheless revealed statistically significant effects (PERMANOVA; sex $\times$ treatment: $F=0.9, \mathrm{R}^{2}=0.04$, $\mathrm{p}=0.564$; sex: $\mathrm{F}=2.3, \mathrm{R}^{2}=0.05, \mathrm{p}=0.042$; treatment: $\left.\mathrm{F}=2.4, \mathrm{R}^{2}=0.10, \mathrm{p}=0.015\right)$. For secretions of female beetles alone there was a marginally significant treatment effect (PERMANOVA; $\mathrm{F}=2.0, \mathrm{R}^{2}=0.17, \mathrm{p}=0.057$ ). In post hoc tests, and also visible in the NMDS plot (Fig. 1b), this effect could be attributed to differences in secretion composition between naïve and wounded females $\left(F=4.4, R^{2}=0.24, p=0.006\right)$, whereas there were no significant differences between naïve and primed $\left(F=0.9, R^{2}=0.06, p=0.472\right)$, and between wounded and primed females $\left(F=1.4, \mathrm{R}^{2}=0.09, \mathrm{p}=0.365\right)$. Analysing male beetles separately, the relative composition of the stink gland secretion seemed visually quite similar in all three treatment groups (Fig. 1c), and likewise there was no significant treatment effect (PERMANOVA; $F=1.4, \mathrm{R}^{2}=0.12, \mathrm{p}=0.180$ ). See Figs $\mathrm{S} 1$ and $\mathrm{S} 2$ for visualisation of the contribution of individual secretion features to the separation shown in NMDS plots. In the dataset acquired $72 \mathrm{~h}$ after treatment, there was only a slight separation of relative secretion composition between sexes but not with regard to treatment groups (Fig. S3a), and accordingly, only a marginally significant sex effect was revealed (PERMANOVA; 
sex $\times$ treatment: $F=0.2, R^{2}=0.01, p=0.989 ;$ sex: $F=1.9, R^{2}=0.04, p<0.092 ;$ treatment: $F$ $\left.=0.9, \mathrm{R}^{2}=0.04, \mathrm{p}=0.485\right)$. Female and male beetles were nevertheless separately tested for treatment effects but none of those were significant (PERMANOVA; $F=0.6, \mathrm{R}^{2}=0.05, \mathrm{p}=$ 0.802; males: $\mathrm{F}=0.6, \mathrm{R}^{2}=0.06, \mathrm{p}=0.854$ ), or visible in NMDS plots (Figs $\mathrm{S} 3 \mathrm{~b}, \mathrm{c}$ ). No changes in relative composition of gland secretion features due to treatments were suggested by NMDS and PERMANOVA results; thus, analysis of target features was in the following only done for the dataset acquired $24 \mathrm{~h}$ after the treatment. the relative amount of the feature with RI 1015 was reduced in both primed and wounded females (Kruskal-Wallis test, females: $\chi^{2}=9.84, \mathrm{df}=2, \mathrm{p}=0.034$, males: $\chi^{2}=1.72, \mathrm{df}=2, \mathrm{p}$ $=0.49)$, whereas the feature with RI 1473 was specifically increased only in wounded males

(Kruskal-Wallis test, females: $\chi^{2}=3.43, \mathrm{df}=2, \mathrm{p}=0.37$, males: $\chi^{2}=9.27, \mathrm{df}=2, \mathrm{p}=0.034$ ).

We further examined MBQ, EBQ and 1-C15-ene in more detail because of their known biological role in beetle communication (Verheggen et al., 2007) and as antimicrobial agents (Pedrini et al., 2010; Prendeville \& Stevens, 2002; Yezerski et al., 2007). Whereas the relative composition of the three compounds MBQ, EBQ and their carrier 1-C15-ene did not change in relation to treatment and sex (Fig. 3a, c, e; LM; EBQ: $F=1.071, \mathrm{df}=5, \mathrm{p}=0.49$, MBQ: $\mathrm{F}$ $=1.511, \mathrm{df}=5, \mathrm{p}=0.37,1-\mathrm{C} 15$-ene: $\mathrm{F}=0.69, \mathrm{df}=5, \mathrm{p}=0.63)$, we found strong treatment and sex differences in their absolute amounts (Fig. 3b, d, f; LM; EBQ: sex $\times$ treatment: $F=$ $1.26, \mathrm{df}=2, \mathrm{p}=0.3$, treatment: $\mathrm{F}=4.65, \mathrm{df}=2, \mathrm{p}=0.015, \mathrm{sex}: \mathrm{F}=4.7, \mathrm{df}=2, \mathrm{p}=0.036$, MBQ: $\operatorname{sex} \times$ treatment: $F=1.69, \mathrm{df}=2, \mathrm{p}=0.1975$, treatment: $\mathrm{F}=4.3, \mathrm{df}=2, \mathrm{p}=0.02$, sex: $\mathrm{F}=4.58, \mathrm{df}=2, \mathrm{p}=0.038,1-\mathrm{C} 15$-ene: Kruskal-Wallis test (females) $\chi^{2}=9.75, \mathrm{df}=2, \mathrm{p}=$ 0.017, Kruskal-Wallis test (males) $\chi^{2}=3.28, \mathrm{df}=2, \mathrm{p}=0.19$ ). Although the absolute amount of compounds cannot be precisely controlled during experimental handling (see Methods), we found a consistent increase in absolute amount of all target compounds in wounded females, but this was not statistically different from primed females for EBQ and MBQ (Fig 3b, d). 
Therefore, our results indicate that relative and absolute composition of glandular secretions in T. castaneum change in respect to treatment and sex and that wounding induces different physiological signatures from priming.

\subsection{Cuticular hydrocarbons}

In total, $20 \mathrm{CHCs}$ were putatively identified in the dataset. These consisted of seven $n$ alkanes (C25-C31), six 3- and 4-methyl-branched alkanes and seven internally methylbranched alkanes of which one was a dimethyl alkane (Table S2). The RIs of all identified CHCs did not differ by more than \pm 4 from the RI values proposed by the literature (Lockey 1978; Alnajim et al. 2019; Awater-Salendo et al. 2020). The dominant CHCs in both naïve females and males were $n-\mathrm{C} 29,3-\mathrm{MeC} 27,13-\mathrm{MeC} 27$ and $n$-C27, all with a higher proportion than $10 \%$ (Table S2).

NMDS plots resulted in a clear separation of $\mathrm{CHC}$ profiles based on relative composition of males and females and also in a separation of CHC profiles of beetles from different treatments within sexes (Fig. 4a). Accordingly, the influence of these factors, but not of their interaction, on the variation in the dataset was significant (PERMANOVA; sex $\times$ treatment: $F=0.4, R^{2}=0.01, p=0.827$; sex: $F=60.8, R^{2}=0.60, p<0.001$; treatment: $F=$ $\left.4.5, \mathrm{R}^{2}=0.09, \mathrm{p}=0.004\right)$. Scores of individual CHCs on the NMDS plot (Fig. $\left.4 \mathrm{~b}\right)$ and heatmaps comparing relative values of CHCs to naïve males and females (Fig. S4) visualised groups of CHCs differentiating beetles by sex. Most obviously, male CHCs harboured higher proportions of rather long-chain $n$ - and also methyl alkanes, especially of the cluster comprising 3-MeC29, $n$-C30 and $n$-C31 (Fig. 4b, Fig. S4). In contrast, the CHC profile of female beetles was characterised by higher proportions of rather short-chain methyl alkanes, especially of the cluster comprising 10-/11-/12-MeC26, 3-MeC27 and 13-MeC27 (Fig. 4b, Fig. S4). 

those of beetles of both treatments, but separated stronger from $\mathrm{CHC}$ profiles of wounded than those of primed beetles (Fig. 4c), which fits the statistically significant treatment effect (PERMANOVA; $\mathrm{F}=2.5, \mathrm{R}^{2}=0.25, \mathrm{p}=0.023$ ). In post hoc tests, $\mathrm{CHC}$ profiles of naïve beetles differed significantly from those of wounded $\left(F=4.8, R^{2}=0.33, p=0.006\right)$, but not from those of primed beetles $\left(\mathrm{F}=2.0, \mathrm{R}^{2}=0.17, \mathrm{p}=0.153\right)$, while $\mathrm{CHC}$ profiles of wounded and primed beetles were quite similar $\left(F=0.6, R^{2}=0.06, p=0.630\right)$. As inferred from the

CHC scores in the NMDS plot and heatmaps showing treatment-related differences relative to naïve beetles, higher proportions of shorter methyl alkanes (C26-C29) characterised CHC profiles of both wounded and primed females in comparison to those of naïve females (Fig. $4 c, d)$. The CHC profiles of naïve females had higher proportions of comparatively longer $n$ alkanes (C29-C31) and also of 3-MeC31 (Fig. 4c, d). NMDS plots, where profiles of naïve beetles separated from those of wounded and primed ones (Fig. 4e), which was mirrored in a significant treatment effect (PERMANOVA; F = 2.4, $\left.\mathrm{R}^{2}=0.24, \mathrm{p}=0.009\right)$. Post hoc tests revealed similar patterns as in females, with CHC profiles of naïve males differing significantly from those of wounded $\left(F=3.8, R^{2}=0.28, p=\right.$ 0.009), but not from CHC profiles of primed males $\left(F=2.1, \mathrm{R}^{2}=0.18, \mathrm{p}=0.110\right)$, whereas slightly differed (Fig. 4e, f). 


\section{Discussion}

As group-living animals that share the same food resources and living space at high

environment using stink gland secretions that have a major influence on the microbial load of

flour (Sokoloff, 1974; Van Wyk et al., 1959), thereby constructing the niche in which adults and their offspring live in. As some of the secreted substances have antimicrobial activity, the secretions are also considered a form of 'external immunity' (Joop et al., 2014; Otti et al., 2014), which, like an internal immune system, needs to act prophylactically and be adjusted to the anticipated demands. This is especially important from the aspect of parental care (Clutton-Brock, 1991; Trivers, 1972), as adults may modulate their stink gland secretion composition upon detected pathogen risks to protect their offspring, which do not possess these glands. Indeed, in our experiment we found a female-specific increase in the absolute amount of target compounds from stink gland secretions (Fig. 3a, c, e) that was significant only for the wounded, and less so primed females. These results could reflect different reproductive and brood-care investments between females and males, as females invest more resources into immunity and longevity (Bateman, 1948; Rolff, 2002) or into brood protection from parasites (Trivers, 1972). In contrast to the observed change in the absolute amounts of MBQ, EBQ and 1-C15-ene, we found no change in the relative composition of these or other features in our dataset, except in the two yet unidentified sex-specific features (RI 1015 females, RI 1473 males) that were overall represented in lower relative abundance (Fig 1. a, b). Whereas the relative intensity of RI 1015 was lower in both wounded and primed females, feature RI 1473 was relatively higher in wounded males. The two unidentified features of sexspecific relative abundance responding to immune treatments may serve various sexdifferential functions as seen in Tenebrio molitor such as investment in offspring (Nielsen \& 
Holman, 2012) or attractiveness for mates (Rantala et al., 2002; Sadd et al., 2006; Worden et al., 2000).

In our study, wounding revealed to have a more pronounced effect on the chemical composition of stink gland secretions than priming, compared to secretions from naive control beetles (Fig. 3b, d, f). This may result from the specificity of the immune response against the bacterium (here Btt) used for priming (Ferro et al., 2019; Roth et al., 2009), whereas compounds from stink gland secretions, being broad in their antimicrobial activity, may provide protection against yet unknown pathogens invading the body cavity, and could thus be a more appropriate response after wounding. For example, BQs are important for protection against various bacteria and fungi (Joop et al., 2014; Pedrini et al., 2015; Sawada et al., 2020), which might gain access to the insects' body cavity after wounding. The observed differences in quinone production may also result from a resource trade-off between internal and external immunity; tyrosine is a limiting resource for both, the PO cascade within the internal immune defence and the production of quinones for secretion (Joop et al., 2014; Otti et al., 2014). The strong and lasting activation of PO shown in T. castaneum upon Bt infection (Behrens et al., 2014) might compete for tyrosine that is also needed for the production of quinones. The broad and unspecific responses turned on after wounding seem to be costly (Schulz et al., 2019), and some of these costs might be explained by the increased production of antimicrobial secretion compounds.

Apart from serving as antimicrobials and thus allelochemicals, BQs and alkenes in stink gland secretions also lead to dose-dependent behavioural responses in T. castaneum, i.e. serve as pheromones (Suzuki, 1985; Verheggen et al., 2007). Low amounts of quinones trigger aggregation, whereas high amounts become repellent or even toxic to conspecifics (Chapman, 1926; Roth \& Howland, 1941; Sokoloff, 1974). The BQs and alkenes act in concert with an aggregation pheromone, 4,8-dimethyldecanal, and mediate dispersal of conspecifics (Duehl et al., 2011; Verheggen et al., 2007). If wounding, e.g., via intraspecific 
cannibalism or interspecific competition, stimulates increased secretion of BQs, this can in turn signal overcrowding (Faustini \& Burkholder, 1987; Verheggen et al., 2007) and result in further interference competition mediated by BQs (Khan et al., 2018; Sonleitner \& Gutherie, 1991) or even dispersal (Duehl et al., 2011; Ogden, 1969), thereby influencing group dynamics and population size. Because flour conditioning and chemical cues affect the development, behaviour and survival of beetles (Joop et al., 2014), we hypothesise that differential changes in stink gland secretions in response to individual immune experiences are likely contributing to niche construction of flour beetles (Gokhale et al., 2017; Joop et al., 2014) by 1) regulating the pathogenic threat experienced by themselves and other conspecifics (Joop et al., 2014) and 2) mediating aggregation or dispersal behaviours of conspecifics (Duehl et al., 2011). The later process prompts the adjacent conspecifics to disperse into new environments, i.e. "relocational niche construction" or "niche choice". sex on the CHC profiles of adult flour beetles. The CHC profiles of male and female beetles differed strongly in their relative composition (Fig. 4a, b). Sexual dimorphisms of CHC profiles are well documented in various invertebrate species (Jallon \& David, 1987; Müller \& Müller, 2016; Thomas \& Simmons, 2008), but have, to our knowledge, not yet been demonstrated for T. castaneum. CHCs play an important role for communication between the sexes (Geiselhardt et al., 2009; Howard \& Blomquist, 2005; Müller \& Müller, 2016; Thomas \& Simmons, 2008), and such communication can also be influenced by immune status. For example, in Tenebrio molitor immune challenge modulates sexual signals particularly in males by altering their $\mathrm{CHC}$ profiles and volatile odours and thus turns them more attractive to females (Nielsen \& Holman, 2012; Sadd et al., 2006). This change in chemical profiles 

and immune-primed beetles changed within one day compared to the naïve controls, and these changes were even more pronounced than for secretions (Fig. 4). The higher proportions of shorter methyl-branched alkanes characterized the immune-stimulated beetles, both wounded and primed, whereas higher proportions of $n$-alkanes were characteristic for the naive beetles involved in the production of methyl alkanes (Blomquist \& Ginzel, 2021; Holze et al., 2021). In comparison to $n$-alkanes (linear alkanes), methyl alkanes were shown to be more important in cue recognition (reviewed in van Zweden \& d'Ettorre, 2010) and to mediate detection of $T$. castaneum larvae by parasitoids (Awater-Salendo et al., 2020). The regulation of methyl alkanes upon immune stimulation has been reported in other host-parasite systems as well (Baracchi et al., 2012; Richard et al., 2008). The greater metabolic cost associated with producing these compounds over $n$-alkanes (Nelson, 1993), along with the variability in the position of methyl branching suggest that methyl alkanes may have an adaptive value in hostparasite interactions. It is also known that many of the CHCs possess antimicrobial properties (Pedrini et al.,2013). The synthesis of insect CHCs and the assimilation/alteration of these compounds during infection by entomopathogenic fungi such as Beauveria bassiana may represent an example of a co-evolutionary arms race (Pedrini et al., 2013).

Although differences in the relative $\mathrm{CHC}$ profiles between the wounded and primed beetles were statistically marginal, the NMDS plots suggested a tendency for the CHC bouquets of wounded beetles, both males and females, to be more strongly separated from those of the naïve beetles than those of the primed group (Fig. 4a, c, e). This is in line with our previous observations that wounding is more effective than priming in eliciting responses among interacting conspecifics (Peuß et al., 2015 and unpublished data). In contrast, Richard 

interacted with the treated workers. Most likely, wounding triggers flour beetles to establish a physiological state of heightened 'alertness' that leads to stronger changes in CHC profiles, whereas immune priming carries more information and induces additional physiological and immunological responses that mediate more tailored defences against certain types of pathogens, i.e., specific responses (Ferro et al., 2019; Roth et al., 2009). Taken together, our study suggests that the changed $\mathrm{CHC}$ bouquet of wounded beetles is a potential cue for the detection of immune experience in conspecifics, which may lead to the described changes in immune status and Hsp83/Hsp90 expression (Peuß et al., 2015). However, additional experimental tests are needed to prove this.

\section{Conclusions}

Our study highlights the potential role of chemical profiles that may mediate the intertwined processes of immunity and niche construction in the red flour beetle (Müller et al. 2020). While both stink gland secretions and CHCs are potentially important infochemicals, they might serve different functions. The effects of immune stimulation on secretions were mostly seen in females, whereas the composition of CHCs was affected in both sexes. This supports the view that CHCs might carry information of individual immune experience into the group. In the red flour beetle, the social transfer of such information even has the potential to mediate adaptation via evolutionary capacitance (Peuß et al., 2015). More generally, these results not only demand for the exploration of similar phenomena in related systems with 'external immunity', including other important pest organisms such as the Red Palm Weevil, 


\section{Funding}

519 This research was funded by the German Research Foundation (DFG) as part of the SFB TRR $520212\left(\mathrm{NC}^{3}\right)$ - Project numbers 316099922 (metabolomics platform), 396777467 (granted to $521 \mathrm{CM}$ ) and 396780003 (granted to JK).

\section{Author contributions}

JK and CM conceived the ideas. JK, CM, LJT, LKL and RR planned the experimental procedure. LKL and RR carried out the experiments and analysed the raw data together with LJT. BM and LJT carried out the statistical analyses. LKL, RR, LJT, BM and JK wrote the first draft of the manuscript and all authors contributed to the article and approved the submitted version.

\section{References}

531

Alabi, T., Michaud, J. P., Arnaud, L., \& Haubruge, E. (2008). A comparative study of cannibalism and predation in seven species of flour beetle. Ecological Entomology $\mathbf{5 0}$ (6), 967-976. https://doi.org/10.1111/j.1365-2311.2008.01020.x

Alnajim, I., Du, X., Lee, B., Agarwal, M., Liu, T., \& Ren, Y. (2019). New method of analysis of lipids in Tribolium castaneum (Herbst) and Rhyzopertha dominica (Fabricius) insects by direct immersion solid-phase microextraction (DI-SPME) coupled with GC-MS. Insects 10 (10), 363. https://doi.org/10.3390/insects10100363

Arakawa, H., Cruz, S., \& Deak, T. (2011). From models to mechanisms: odorant communication as a key determinant of social behavior in rodents during illnessassociated states. Neuroscience and Biobehavioral Reviews, 35 (9), 1916-1928. https://doi.org/10.1016/j.neubiorev.2011.03.007

Awater-Salendo, S., Schulz, H., Hilker, M., \& Fürstenau, B. (2020). The importance of methyl-branched cuticular hydrocarbons for successful host recognition by the larval ectoparasitoid Holepyris sylvanidis. Journal of Chemical Ecology, 46 (11-12), 1032 1046. https://doi.org/10.1007/s10886-020-01227-w 
Baracchi, D., Fadda, A., \& Turillazzi, S. (2012). Evidence for antiseptic behaviour towards sick adult bees in honey bee colonies. Journal of Insect Physiology, 58 (12), 15891596. https://doi.org/10.1016/j.jinsphys.2012.09.014

Bateman, A. J. (1948). Intra-sexual selection in Drosophila. Heredity, 2 (Pt. 3), 349-368. https://doi.org/10.1038/hdy.1948.21

Behrens, S., Peuß, R., Milutinović, B., Eggert, H., Esser, D., Rosenstiel, P., Schulenburg, H., Bornberg-Bauer, E., \& Kurtz, J. (2014). Infection routes matter in population-specific responses of the red flour beetle to the entomopathogen Bacillus thuringiensis. BMC Genomics, 15, 445. https://doi.org/10.1186/1471-2164-15-445

Behringer, V., Preis, A., Wu, D. F., Crockford, C., Leendertz, F. H., Wittig, R. M., \& Deschner, T. (2020). Urinary cortisol increases during a respiratory outbreak in wild chimpanzees. Frontiers in Veterinary Science, 7, 485. https://doi.org/10.3389/fvets.2020.00485

Benjamini, Y., \& Hochberg, Y. (1995). Controlling the false discovery rate: A practical and powerful approach to multiple testing. Journal of the Royal Statistical Society, 57(1), 289-300. https://doi.org/10.1111/j.2517-6161.1995.tb02031.x

Blomquist, G. J., \& Bagnères, A.-G. (2010). Insect hydrocarbons: Biology, Biochemistry, and Chemical Ecology. Cambridge University Press. https://play.google.com/store/books/details?id=brc3SLVzo-oC

Blomquist, G. J., \& Ginzel, M. D. (2021). Chemical ecology, biochemistry, and molecular biology of insect hydrocarbons. Annual Review of Entomology, 66, 45-60. https://doi.org/10.1146/annurev-ento-031620-071754

Cerenius, L., Lee, B. L., \& Söderhäll, K. (2008). The proPO-system: pros and cons for its role in invertebrate immunity. Trends in Immunology 29 (6), 263-271. https://doi.org/10.1016/j.it.2008.02.009 
571 Chapman, Royal N. (1926). Inhibiting the process of metamorphosis in the confused flour

572

573

574

575

576

577

578

579

580

581

582

583

584

585

586

587

588

589

590

591

592

593

594

beetle (Tribolium confusum, Duval). The Journal of Experimental Zoology, 45 (1), 293299. https://doi.org/10.1002/jez.1400450110

Clutton-Brock, T. H. (1991). The evolution of parental care. https://books.google.com/books/about/The_Evolution_of_Parental_Care.html?hl=\&id= 3oOqQgAACAAJ

Cremer, S., Pull, C. D., \& Fürst, M. A. (2018). Social immunity: emergence and evolution of colony-level disease protection. Annual Review of Entomology, 63, 105-123. https://doi.org/10.1146/annurev-ento-020117-043110

Csata, E., Timuş, N., Witek, M., Casacci, L. P., Lucas, C., Bagnères, A.-G., SztencelJabłonka, A., Barbero, F., Bonelli, S., Rákosy, L., \& Markó, B. (2017). Lock-picks: fungal infection facilitates the intrusion of strangers into ant colonies. Scientific Reports, 7, 46323. https://doi.org/10.1038/srep46323

De Moraes, C. M., Stanczyk, N. M., Betz, H. S., Pulido, H., Sim, D. G., Read, A. F., \& Mescher, M. C. (2014). Malaria-induced changes in host odors enhance mosquito attraction. Proceedings of the National Academy of Sciences of the United States of America, 111 (30), 11079-11084. https://doi.org/10.1073/pnas.1405617111

Duehl, A. J., Arbogast, R. T., \& Teal, P. E. A. (2011). Density-related volatile emissions and responses in the red flour beetle, Tribolium castaneum. Journal of Chemical Ecology, 37 (5), 525-532. https://doi.org/10.1007/s10886-011-9942-3

Faustini, D. L., \& Burkholder, W. E. (1987). Quinone-aggregation pheromone interaction in the red flour beetle. Animal Behaviour, 35 (2), 601-603. https://doi.org/10.1016/S00033472(87)80289-0

Ferro, K., Ferro, D., Corrà, F., Bakiu, R., Santovito, G., \& Kurtz, J. (2017). Cu,Zn superoxide dismutase genes in : evolution, molecular characterisation, and gene expression during 
immune priming. Frontiers in Immunology, 8, 1811. https://doi.org/10.3389/fimmu.2017.01811

Ferro, K., Peuß, R., Yang, W., Rosenstiel, P., Schulenburg, H., \& Kurtz, J. (2019). Experimental evolution of immunological specificity. Proceedings of the National Academy of Sciences of the United States of America, 116 (41), 20598-20604. https://doi.org/10.1073/pnas.1904828116

Gallagher, J. D., Siva-Jothy, M. T., \& Evison, S. E. F. (2018). Social cues trigger differential immune investment strategies in a non-social insect, Tenebrio molitor. Biology Letters 14 (2), 20170709. https://doi.org/10.1098/rsbl.2017.0709

Geiselhardt, S., Otte, T., \& Hilker, M. (2009). The role of cuticular hydrocarbons in male mating behavior of the mustard leaf beetle, Phaedon cochleariae (F.). Journal of Chemical Ecology, 35 (10), 1162-1171. https://doi.org/10.1007/s10886-009-9704-7

Gokhale, C. S., Traulsen, A., \& Joop, G. (2017). Social dilemma in the external immune system of the red flour beetle? It is a matter of time. Ecology and Evolution, 7 (17), 6758-6765. https://doi.org/10.1002/ece3.3198

Hernández López, J., Riessberger-Gallé, U., Crailsheim, K., \& Schuehly, W. (2017). Cuticular hydrocarbon cues of immune-challenged workers elicit immune activation in honeybee queens. Molecular Ecology, 26 (11), 3062-3073. https://doi.org/10.1111/mec. 14086

Holze, H., Schrader, L., \& Buellesbach, J. (2021). Advances in deciphering the genetic basis of insect cuticular hydrocarbon biosynthesis and variation. Heredity, 126 (2), 219-234. https://doi.org/10.1038/s41437-020-00380-y

Howard, R. W., \& Blomquist, G. J. (2005). Ecological, behavioral, and biochemical aspects of insect hydrocarbons. Annual Review of Entomology, 50, 371-393. https://doi.org/10.1146/annurev.ento.50.071803.130359 
Jallon, J.-M., \& David, J. R. (1987). Variations in cuticular hydrocarbons among the eight species of Drosophila Melanogaster subgroup. Evolution; International Journal of Organic Evolution, 41 (2), 294-302. https://doi.org/10.1111/j.15585646.1987.tb05798.x

Joop, G., Roth, O., Schmid-Hempel, P., \& Kurtz, J. (2014). Experimental evolution of external immune defences in the red flour beetle. Journal of Evolutionary Biology, 27 (8), 1562-1571. https://doi.org/10.1111/jeb.12406

Kappeler, P. M., Cremer, S., \& Nunn, C. L. (2015). Sociality and health: impacts of sociality on disease susceptibility and transmission in animal and human societies. Philosophical Transactions of the Royal Society of London. Series B, Biological Sciences, 370 (1669). https://doi.org/10.1098/rstb.2014.0116

Khan, I., Prakash, A., Issar, S., Umarani, M., Sasidharan, R., Masagalli, J. N., Lama, P., Venkatesan, R., \& Agashe, D. (2018). Female density-dependent chemical warfare underlies fitness effects of group sex ratio in flour beetles. The American Naturalist, 191 (3), 306-317. https://doi.org/10.1086/695806

Kolde, R. (2019). pheatmap: Pretty Heatmaps. R package version 1.0.12. https://CRAN.Rproject.org/package $=$ pheatmap

Konrad, M., Vyleta, M. L., Theis, F. J., Stock, M., Tragust, S., Klatt, M., Drescher, V., Marr, C., Ugelvig, L. V., \& Cremer, S. (2012). Social transfer of pathogenic fungus promotes active immunisation in ant colonies. PLoS Biology, 10 (4), e1001300. https://doi.org/10.1371/journal.pbio.1001300

Kováts, E. (1958). Gas-chromatographische charakterisierung organischer verbindungen. teil 1: retentionsindices aliphatischer halogenide, alkohole, aldehyde und ketone. Helvetica Chimica Acta 41 (7), 1915-1932. https://doi.org/10.1002/hlca.19580410703 
645 Lehmann, S. (2015). Biology of odoriferous defensive stink glands of the red flour beetle

646

647

648

649

650

651

652

653

654

655

656

657

658

659

660

661

662

663

664

665

666

667

668

669

670

Tribolium castaneum [Niedersächsische Staats-und Universitätsbibliothek Göttingen]. https://d-nb.info/1076673619/34

Leonhardt, S. D., Menzel, F., Nehring, V., \& Schmitt, T. (2016). Ecology and evolution of communication in social insects. Cell, 164 (6), 1277-1287. https://doi.org/10.1016/j.cell.2016.01.035

Li, J., Lehmann, S., Weißbecker, B., Ojeda Naharros, I., Schütz, S., Joop, G., \& Wimmer, E. A. (2013). Odoriferous defensive stink gland transcriptome to identify novel genes necessary for quinone synthesis in the red flour beetle, Tribolium castaneum. PLoS Genetics, 9 (7), e1003596. https://doi.org/10.1371/journal.pgen.1003596

Little, T. J., \& Kraaijeveld, A. R. (2004). Ecological and evolutionary implications of immunological priming in invertebrates. Trends in Ecology \& Evolution, 19 (2), 58-60. https://doi.org/10.1016/j.tree.2003.11.011

Lockey, K. H. (1978). Hydrocarbons of adult Tribolium castaneum hbst. and Tribolium confusum duv. (coleoptera: tenebrionidae). Comparative Biochemistry and Physiology Part B: Comparative Biochemistry 61 (3), 401-407. https://doi.org/10.1016/03050491(78)90145-1

Loconti, J. D., \& Roth, L. M. (1953). Composition of the odorous secretion of Tribolium castaneum. Annals of the Entomological Society of America 46 (2), 281-289. https://doi.org/10.1093/aesa/46.2.281

Lopes, P. C. (2020). We are not alone in trying to be alone. Frontiers in Ecology and Evolution, 8, 172. https://doi.org/10.3389/fevo.2020.00172

Martinez Arbizu, P. (2020). pairwiseAdonis: Pairwise multilevel comparison using adonis. $R$ package version 0.4. https://github.com/pmartinezarbizu/pairwiseAdonis

Masri, L., \& Cremer, S. (2014). Individual and social immunisation in insects. Trends in Immunology, 35 (10), 471-482. https://doi.org/10.1016/j.it.2014.08.005 
671 Milutinović, B., \& Kurtz, J. (2016). Immune memory in invertebrates. Seminars in

672

673

674

675

676

677

678

679

680

681

682

683

684

685

686

687

688

689

690

691

692

693

694

695

Immunology, 28 (4), 328-342. https://doi.org/10.1016/j.smim.2016.05.004

Milutinović, B., Stolpe, C., Peuß, R., Armitage, S. A. O., \& Kurtz, J. (2013). The red flour beetle as a model for bacterial oral infections. PloS One, 8 (5), e64638. https://doi.org/10.1371/journal.pone.0064638

Mondet, F., Blanchard, S., Barthes, N., Beslay, D., Bordier, C., Costagliola, G., Hervé, M. R., Lapeyre, B., Kim, S. H., Basso, B., Mercer, A. R., \& Le Conte, Y. (2021). Chemical detection triggers honey bee defense against a destructive parasitic threat. Nature Chemical Biology. https://doi.org/10.1038/s41589-020-00720-3

Müller, C., Caspers, B. A., Gadau, J., \& Kaiser, S. (2020). The power of infochemicals in mediating individualized niches. In Trends in Ecology \& Evolution 35 (11), 981-989. https://doi.org/10.1016/j.tree.2020.07.001

Müller, T., \& Müller, C. (2016). Consequences of mating with siblings and nonsiblings on the reproductive success in a leaf beetle. Ecology and Evolution, 6 (10), 3185-3197. https://doi.org/10.1002/ece3.2103

Nelson, D. R. (1993). Methyl-branched lipids in insects. Insect Lipids: Chemistry, Biochemistry and Biology, 271-315. https://books.google.de/books?hl=en\&lr=\&id=fA5IezUO8kC\&oi=fnd\&pg=PA271\&dq=Methylbranched + lipids + in + insects. + In+Insect + Lipids: + Chemistry, + Biochemistry,,+ and + Biolo gy\&ots=D7tdKKA_DR\&sig=zLZ6IsxpFCajEXRD-ilmHGmcYQg

Netea, M. G., Joosten, L. A. B., Latz, E., Mills, K. H. G., Natoli, G., Stunnenberg, H. G., O’Neill, L. A. J., \& Xavier, R. J. (2016). Trained immunity: A program of innate immune memory in health and disease. Science, 352 (6284), aff1098. https://doi.org/10.1126/science.aaf1098 
696

697

698

699

700

701

702

703

704

705

706

707

708

709

710

711

712

713

714

715

716

717

718

719

720

Nielsen, M. L., \& Holman, L. (2012). Terminal investment in multiple sexual signals: immune-challenged males produce more attractive pheromones. Functional Ecology $\mathbf{2 6}$ (1), 20-28. https://doi.org/10.1111/j.1365-2435.2011.01914.x

Odling-Smee, J., Erwin, D. H., Palkovacs, E. P., Feldman, M. W., \& Laland, K. N. (2013). Niche construction theory: a practical guide for ecologists. The Quarterly Review of Biology, 88 (1), 4-28. https://doi.org/10.1086/669266

Ogden, J. C. (1969). Effect of components of conditioned medium on behavior in Tribolium confusum. Physiological Zoology, 42 (3), 266-274.

https://doi.org/10.1086/physzool.42.3.30155490

Oksanen, J., Blanchet, F. G., Friendly, M., Kindt, R., Legendre, P., McGlinn, D., Minchin, P. R., O’Hara, R. B., Simpson, G. L., Solymos, P., \& Others. (2020). vegan: Community Ecology Package. R package version 2.5-7. 2020.

Ottensmann, M., Stoffel, M. A., Nichols, H. J., \& Hoffman, J. I. (2018). GCalignR: An R package for aligning gas-chromatography data for ecological and evolutionary studies. PloS One, 13 (6), e0198311. https://doi.org/10.1371/journal.pone.0198311

Otti, O., Tragust, S., \& Feldhaar, H. (2014). Unifying external and internal immune defences. Trends in Ecology \& Evolution, 29 (11), 625-634. https://doi.org/10.1016/j.tree.2014.09.002

Park, T., Mertz, D. B., Grodzinski, W., \& Prus, T. (1965). Cannibalistic predation in populations of flour beetles. Physiological Zoology, 38 (3), 289-321. https://doi.org/10.1086/physzool.38.3.30152840

Pedrini, N., Ortiz-Urquiza, A., Huarte-Bonnet, C., Zhang, S., \& Keyhani, N. O. (2013). Targeting of insect epicuticular lipids by the entomopathogenic fungus Beauveria bassiana: hydrocarbon oxidation within the context of a host-pathogen interaction. Frontiers in Microbiology, 4 (24). https://doi.org/10.3389/fmicb.2013.00024 
Pedrini, N., Ortiz-Urquiza, A., Huarte-Bonnet, C., Fan, Y., Juárez, M. P., \& Keyhani, N. O. (2015). Tenebrionid secretions and a fungal benzoquinone oxidoreductase form competing components of an arms race between a host and pathogen. Proceedings of the National Academy of Sciences of the United States of America, 112 (28), E3651E3660. https://doi.org/10.1073/pnas.1504552112

Pedrini, N., Villaverde, M. L., Fuse, C. B., Dal Bello, G. M., \& Juárez, M. P. (2010). Beauveria bassiana infection alters colony development and defensive secretions of the beetles Tribolium castaneum and Ulomoides dermestoides (Coleoptera: Tenebrionidae). In Journal of Economic Entomology 103 (4), 1094-1099. https://doi.org/10.1603/ec10072

Peterson, R. (2017). Estimating normalization transformations with bestNormalize. https://github.com/petersonR/bestNormalize.

Peuß, R., Eggert, H., Armitage, S. A. O., \& Kurtz, J. (2015). Downregulation of the evolutionary capacitor Hsp90 is mediated by social cues. Proceedings. Biological Sciences / The Royal Society, 282 (1819). https://doi.org/10.1098/rspb.2015.2041

Pham, L. N., Dionne, M. S., Shirasu-Hiza, M., \& Schneider, D. S. (2007). A specific primed immune response in Drosophila is dependent on phagocytes. PLoS Pathogens, 3 (3), e26. https://doi.org/10.1371/journal.ppat.0030026

Prendeville, H. R., \& Stevens, L. (2002). Microbe inhibition by Tribolium flour beetles varies with beetle species, strain, sex, and microbe group. Journal of Chemical Ecology, 28 (6), 1183-1190. https://doi.org/10.1023/a:1016281600915

Pull, C. D., Ugelvig, L. V., Wiesenhofer, F., Grasse, A. V., Tragust, S., Schmitt, T., Brown, M. J., \& Cremer, S. (2018). Destructive disinfection of infected brood prevents systemic disease spread in ant colonies. eLife, 7, e32073. https://doi.org/10.7554/eLife.32073

Pu, Y.-C., Xiang, H.-J., Liang, X.-Y., Wang, Y., Hou, Y.-M., Fu, L., \& Wang, R. (2020). External immune inhibitory efficiency of external secretions and their metabolic 
profiling in red palm weevil, Rhynchophorus ferrugineus (Coleoptera: Curculionidae). Frontiers in Physiology, 10, 1624. https://doi.org/10.3389/fphys.2019.01624

Rantala, M. J., Jokinen, I., Kortet, R., Vainikka, A., \& Suhonen, J. (2002). Do pheromones reveal male immunocompetence? In Proceedings of the Royal Society of London. Series B: Biological Sciences 269 (1501), 1681-1685. https://doi.org/10.1098/rspb.2002.2056

R Core Team. (2018). R: A language and environment for statistical computing (Version 3.5. 2, R Foundation for Statistical Computing, Vienna, Austria, 2018). There Is No Corresponding Record for This Reference. https://www.R-project.org/

R Core Team. (2020). R: A Language and Environment for Statistical Computing (Version 4.0.3, R Foundation for Statistical Computing, Vienna, Austria, 2020). https://www.Rproject.org/

Richard, F.-J., Aubert, A., \& Grozinger, C. M. (2008). Modulation of social interactions by immune stimulation in honey bee, Apis mellifera, workers. BMC Biology, 6, 50. https://doi.org/10.1186/1741-7007-6-50

Rolff, J. (2002). Bateman's principle and immunity. Proceedings. Biological Sciences / The Royal Society, 269 (1493), 867-872. https://doi.org/10.1098/rspb.2002.1959

Rosengaus, R. B., Maxmen, A. B., Coates, L. E., \& Traniello, J. F. A. (1998). Disease resistance: a benefit of sociality in the dampwood termite Zootermopsis angusticollis (Isoptera: Termopsidae). Behavioral Ecology and Sociobiology 44 (2), 125-134. https://doi.org/10.1007/s002650050523

Roth, L. M., \& Howland, R. B. (1941). Studies on the gaseous secretion of Tribolium Confusum Duval I. abnormalities produced in Tribolium Confusum Duval by exposure to a secretion given off by the ddults. Annals of the Entomological Society of America, 34 (1), 151-175. https://academic.oup.com/aesa/article-abstract/34/1/151/147764

Roth, O., Joop, G., Eggert, H., Hilbert, J., Daniel, J., Schmid-Hempel, P., \& Kurtz, J. (2010). Paternally derived immune priming for offspring in the red flour beetle, Tribolium 
castaneum. The Journal of Animal Ecology, 79 (2), 403-413.

https://doi.org/10.1111/j.1365-2656.2009.01617.x

Roth, O., Sadd, B. M., Schmid-Hempel, P., \& Kurtz, J. (2009). Strain-specific priming of resistance in the red flour beetle, Tribolium castaneum. Proceedings. Biological Sciences / The Royal Society, 276 (1654), 145-151. https://doi.org/10.1098/rspb.2008.1157

Rutherford, S. L., \& Lindquist, S. (1998). Hsp90 as a capacitor for morphological evolution. Nature, 396 (6709), 336-342. https://doi.org/10.1038/24550

Sadd, B., Holman, L., Armitage, H., Lock, F., Marland, R., \& Siva-Jothy, M. T. (2006). Modulation of sexual signalling by immune challenged male mealworm beetles (Tenebrio molitor, L.): evidence for terminal investment and dishonesty. In Journal of Evolutionary Biology, 19 (2), 321-325. https://doi.org/10.1111/j.1420$9101.2005 .01062 . \mathrm{x}$

Sawada, M., Sano, T., Hanakawa, K., Sirasoonthorn, P., Oi, T., \& Miura, K. (2020). Benzoquinone synthesis-related genes of Tribolium castaneum confer the robust antifungal host defense to the adult beetles through the inhibition of conidial germination on the body surface. Journal of Invertebrate Pathology, 169, 107298. https://doi.org/10.1016/j.jip.2019.107298

Schulenburg, H., \& Ewbank, J. J. (2007). The genetics of pathogen avoidance in Caenorhabditis elegans. Molecular Microbiology, 66 (3), 563-570. https://doi.org/10.1111/j.1365-2958.2007.05946.x

Schulz, N. K. E., Sell, M. P., Ferro, K., Kleinhölting, N., \& Kurtz, J. (2019). Transgenerational developmental effects of immune priming in the red flour beetle Tribolium castaneum. Frontiers in Physiology, 10, 98. https://doi.org/10.3389/fphys.2019.00098 
Sokoloff, A. (1974). The biology of Tribolium: with special emphasis on genetic aspects (Vol. 3). Oxford University Press, UK. https://www.cabdirect.org/cabdirect/abstract/19780551556

Sonleitner, F. J., \& Gutherie, J. (1991). Factors affecting oviposition rate in the flour beetle Tribolium castaneum and the origin of the population regulation mechanism. Population Ecology, 33 (1), 1-11. https://doi.org/10.1007/bf02514569

Stensmyr, M. C., Dweck, H. K. M., Farhan, A., Ibba, I., Strutz, A., Mukunda, L., Linz, J., Grabe, V., Steck, K., Lavista-Llanos, S., Wicher, D., Sachse, S., Knaden, M., Becher, P. G., Seki, Y., \& Hansson, B. S. (2012). A conserved dedicated olfactory circuit for detecting harmful microbes in Drosophila. Cell, 151 (6), 1345-1357. https://doi.org/10.1016/j.cell.2012.09.046

Stockmaier, S., Stroeymeyt, N., Shattuck, E. C., Hawley, D. M., Meyers, L. A., \& Bolnick, D. I. (2021). Infectious diseases and social distancing in nature. Science, 371 (6533). https://doi.org/10.1126/science.abc8881

Strobl, C., Hothorn, T., \& Zeileis, A. (2009). Party on! A new, conditional variableimportance measure for random forests available in the party package. The R Journal, $\mathbf{1}$, $14-17$.

Strobl, C., Malley, J., \& Tutz, G. (2009). An introduction to recursive partitioning: rationale, application, and characteristics of classification and regression trees, bagging, and random forests. Psychological Methods, 14 (4), 323-348. https://doi.org/10.1037/a0016973

Sun, Q., Haynes, K. F., \& Zhou, X. (2017). Dynamic changes in death cues modulate risks and rewards of corpse management in a social insect. Functional Ecology 31 (3), 697 706. https://doi.org/10.1111/1365-2435.12754 
Suzuki, T. (1985). Presence of another aggregation substance(s) in the frass of the red flour beetles, Tribolium castaneum (Coleoptera: Tenebrionidae). Applied Entomology and Zoology, 20 (1), 90-91. https://doi.org/10.1303/aez.20.90

Thomas, M. L., \& Simmons, L. W. (2008). Sexual dimorphism in cuticular hydrocarbons of the Australian field cricket Teleogryllus oceanicus (Orthoptera: Gryllidae). Journal of Insect Physiology, 54 (6), 1081-1089. https://doi.org/10.1016/j.jinsphys.2008.04.012

Trivers, R. (1972). Parental investment and sexual selection. Sexual Selection \& the Descent of Man, Aldine de Gruyter, 136-179. http://joelvelasco.net/teaching/3330/trivers72parentalinvestment.pdf

Van Wyk, J. H., Hodson, A. C., \& Christensen, C. M. (1959). Microflora associated with the confused flour beetle, Tribolium Confusum. Annals of the Entomological Society of America 52 (4), 452-463. https://doi.org/10.1093/aesa/52.4.452

van Zweden, J. S., \& d'Ettorre, P. (2010). Nestmate recognition in social insects and the role of hydrocarbons. Insect Hydrocarbons: Biology, Biochemistry and Chemical Ecology, 11, 222-243. https://books.google.de/books?hl=en\&lr=\&id=brc3SLVzooC\&oi $=$ fnd\&pg $=$ PA222\&dq $=$ van + Zweden,+ J. + S., + and $+\mathrm{d} \%$ E2\%80\%99Ettorre,$+P .+(20$ 10). $+\% \mathrm{E} 2 \% 80 \% 9 \mathrm{CThe}+$ role + of + hydrocarbons + in + nestmate + recognition, $\% \mathrm{E} 2 \% 80 \% 9$ D+in+Insect+Hydrocarbons:+Biology, + Biochemistry + and + Chemical + Ecology,,+ eds $+\mathrm{G}$ .+ J.+Blomquist+and + A.G. + Bagn $\%$ C3\%A8res $+($ Cambridge: + Cambridge + University + Press $),+222$ \&ots $=3 \mathrm{CmXI}$ vmKWG\&sig=Crzq_IfQUhOKEtpuskNYeerkQR4

Verheggen, F., Ryne, C., Olsson, P. O. C., Arnaud, L., Lognay, G., Högberg, H. E., Persson, D., Haubruge, E., \& Löfstedt, C. (2007). Electrophysiological and behavioral activity of secondary metabolites in the confused flour beetle, Tribolium confusum. Journal of Chemical Ecology, 33 (3), 525-539. https://doi.org/10.1007/s10886-006-9236-3 
847 Via, S. (1999). Cannibalism facilitates the use of a novel environment in the flour beetle, Tribolium castaneum. Heredity, 82 ( Pt 3), 267-275.

849 https://doi.org/10.1038/sj.hdy.6884820

Villaverde, M. L., Patricia Juárez, M., \& Mijailovsky, S. (2007). Detection of Tribolium castaneum (Herbst) volatile defensive secretions by solid phase microextractioncapillary gas chromatography (SPME-CGC). Journal of Stored Products Research $\mathbf{4 3}$ (4), 540-545. https://doi.org/10.1016/j.jspr.2007.03.003 reproductive success in male grain beetles. Animal Behaviour 59 (3), 543-550. https://doi.org/10.1006/anbe.1999.1368

857 Yezerski, A., Ciccone, C., Rozitski, J., \& Volingavage, B. (2007). The effects of a naturally produced benzoquinone on microbes common to flour. Journal of Chemical Ecology 33 


\section{Figures}

861

862

863

864

865

866

867

868

869

870

871

872

873

874

875

876

877

878

879

880

881
Fig. 1 Non-metric multidimensional scaling plots of glandular secretion profiles from Tribolium castaneum beetles of different immune treatment groups ( $n=7-8$ per sex and treatment). Beetles were untreated ('Naïve'), or treated by injection of phosphate buffered saline ('Wounded') or of phosphate buffered saline with heat-killed Bacillus thuringiensis bv. tenebrionis ('Primed'), $24 \mathrm{~h}$ before extraction. Plots show profiles of all beetles (a), or those of females (b) and males separately (c). Datasets comprised relative amounts of 26 chemical features (absolute amounts divided by the total amount of all features considered for a sample) and were transformed with Wisconsin square root double standardisation. Dissimilarities are based on pairwise Kulczynki distances. Data points represent profiles of individual beetles, larger symbols show centroids for treatment groups. The stress value is given at the top right of each plot.
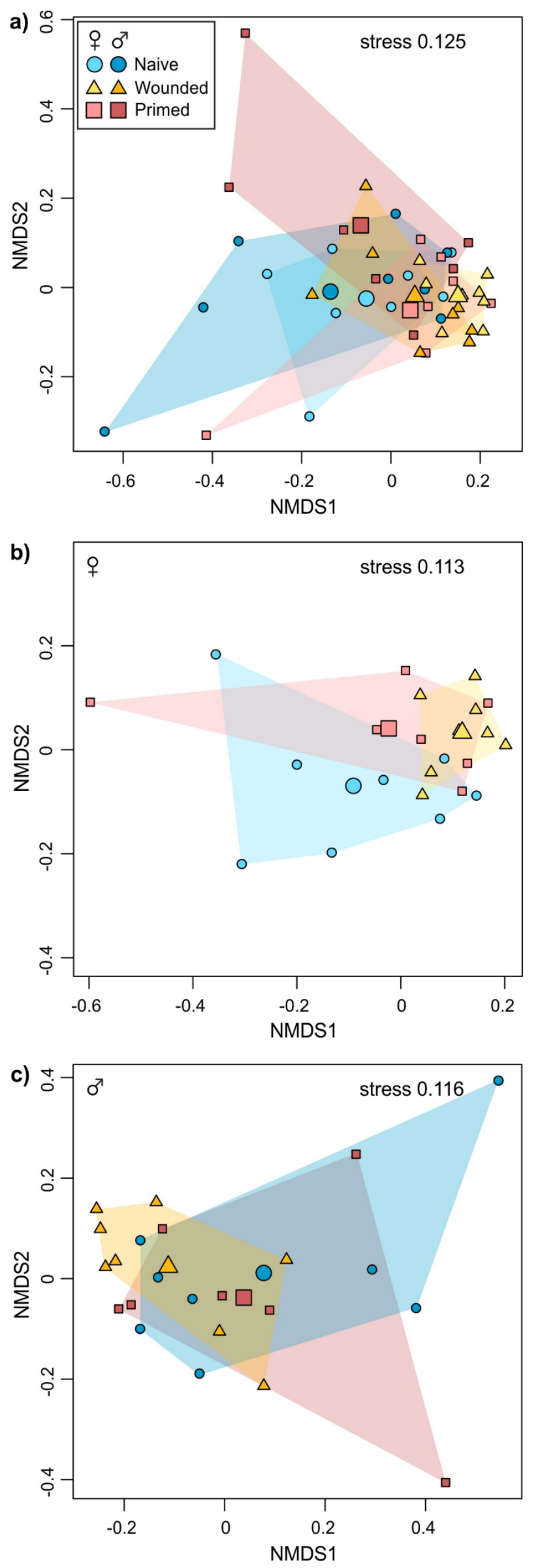

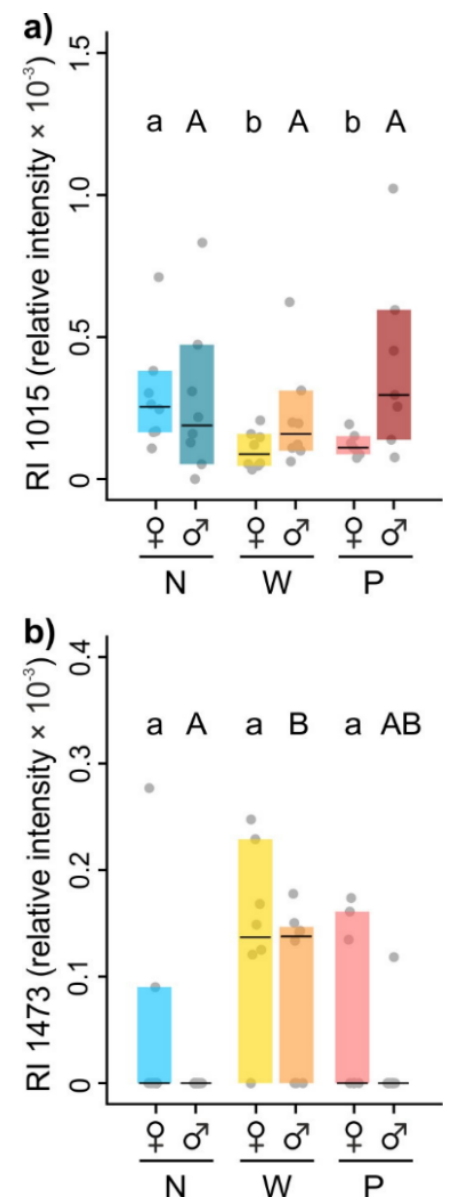

883 Fig. 2 Relative amounts of two features from glandular secretions of Tribolium castaneum 884 beetles of different immune treatment groups ( $n=7-8$ per sex and treatment), suggested as 885 most important for separation of treatment groups within females (feature RI 1015, a) and 886 within males (feature RI 1473, b) in random forest analyses. Beetles were untreated (naïve, 887 'N'), or treated by injection of phosphate buffered saline (wounded, 'W') or of phosphate 888 buffered saline with heat-killed Bacillus thuringiensis bv. tenebrionis (primed, 'P'), $24 \mathrm{~h}$ 889 before extraction. Relative amounts were obtained by dividing absolute amounts by the total 890 amount of all features considered for a sample. Dots represent values of individual beetles, 891 boxes are confidence intervals, lines are medians. Different letters above boxes show 892 significant differences $(\mathrm{p}<0.05)$ between treatment groups within females (lower case letters) 893 and males (upper case letters) in Kruskal-Wallis tests after pairwise comparisons. 

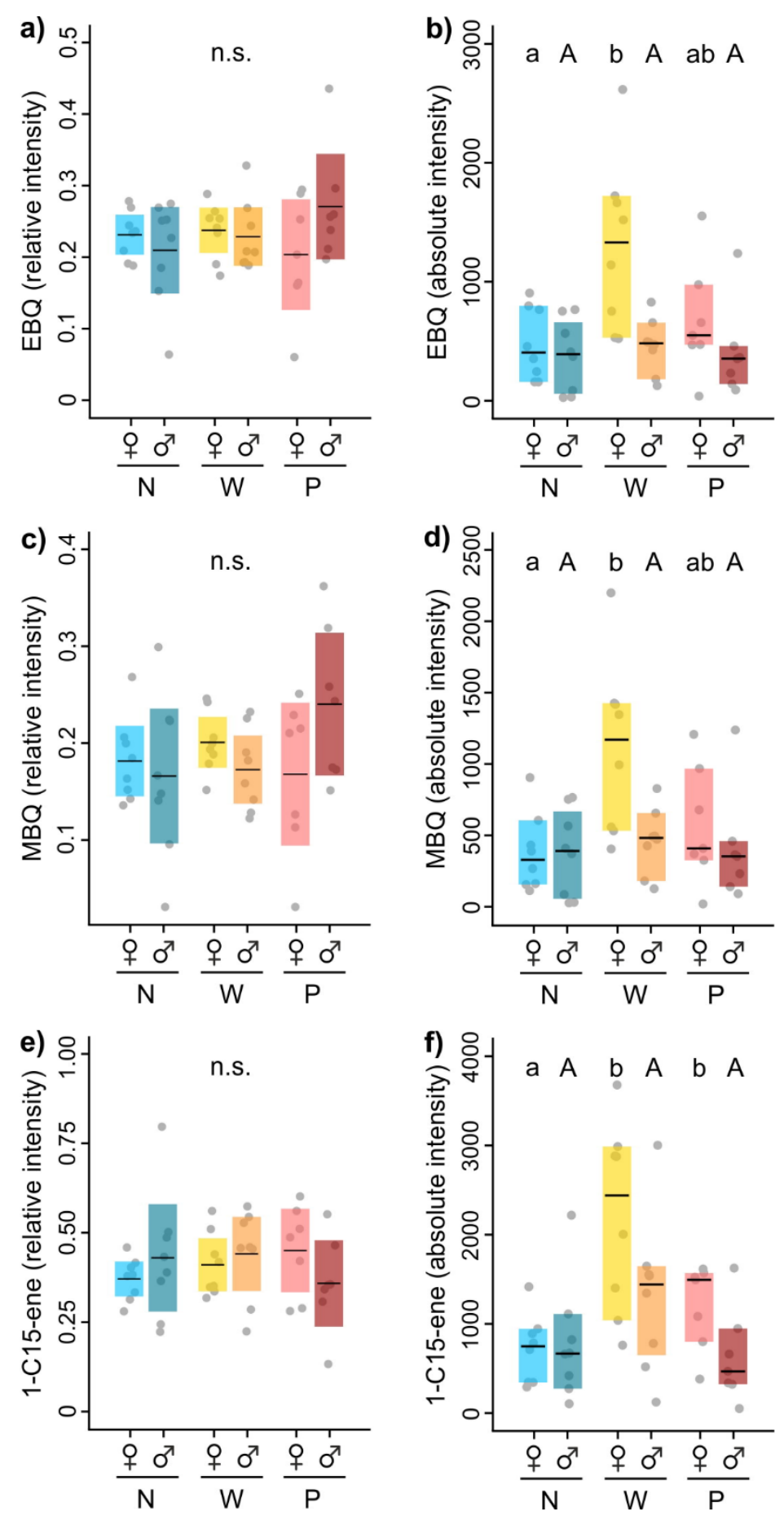

Fig. 3 Relative and absolute amounts of ethyl-1,4-benzoquinone (EBQ), methyl-1,4benzoquinone (MBQ) and 1-pentadecene (1-C15-ene) from glandular secretions of Tribolium castaneum beetles of different immune treatment groups ( $\mathrm{n}=7-8$ per sex and treatment). Beetles were untreated (naïve, 'N'), or treated by injection of phosphate buffered saline (wounded, 'W') or of phosphate buffered saline with heat-killed Bacillus thuringiensis bv. tenebrionis (primed, 'P'), $24 \mathrm{~h}$ before extraction. Relative amounts were obtained by dividing absolute amounts by the total amount of all features considered for a sample. Dots represent values of individual beetles, boxes are confidence intervals, lines are means (a-e) or medians (f). Different letters above boxes show significant differences $(p<0.05)$ between treatment groups within females (lower case letters) and males (upper case letters) in linear models (a-e) or Kruskal-Wallis tests (f) after pairwise comparisons, 'n.s.' is not significant. 

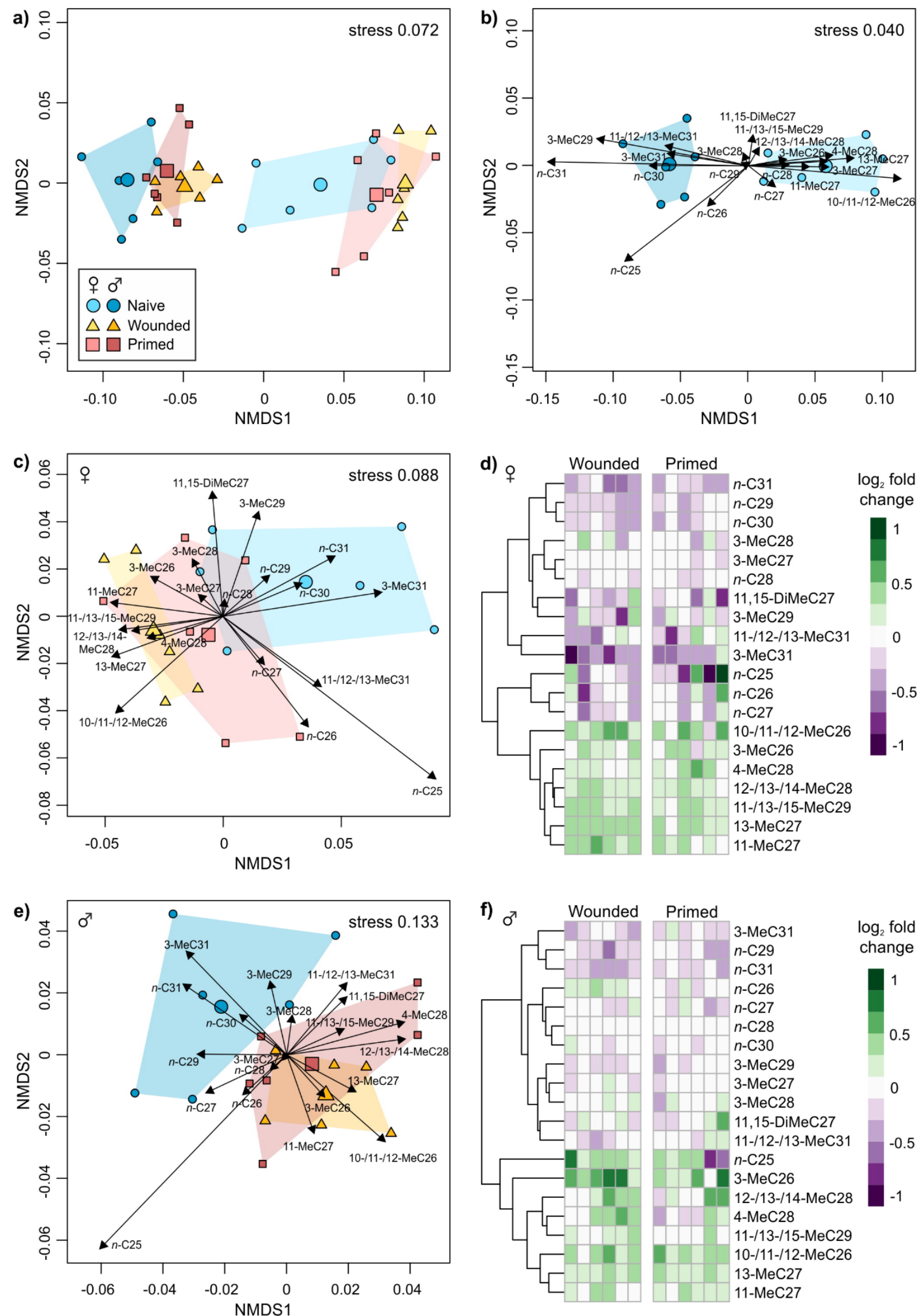

Fig. 4 Non-metric multidimensional scaling (NMDS) plots (a-c, e) and heatmaps (d, f) of

908 cuticular hydrocarbon (CHC) profiles from Tribolium castaneum beetles of different immune 909 treatment groups ( $\mathrm{n}=6$ per sex and treatment). Beetles were untreated ('Naïve'), or treated by 
910 injection of phosphate buffered saline ('Wounded') or of phosphate buffered saline with heat-

911 killed Bacillus thuringiensis bv. tenebrionis ('Primed'), $18 \mathrm{~h}$ before extraction. All plots are

912 based on relative amounts for individual CHCs (absolute amounts divided by the total amount

913 of all CHCs per sample). NMDS plots show profiles of all beetles (a), of naïve beetles

914 separated by sex (b), or of females (c) and males (e) separately. For NMDS plots, datasets

915 comprised $20 \mathrm{CHCs}$ and were transformed with Wisconsin square root double

916 standardisation. Dissimilarities are based on pairwise Kulczynki distances. Data points

917 represent profiles of individual beetles, larger symbols show centroids for treatment groups.

918 The stress value is given at the top right of each plot. Arrows $(\mathbf{b}, \mathbf{c}, \mathbf{e})$ range from zero to

919 positions of expanded weighted average scores of CHCs. Heatmaps show increase and

920 decrease in the proportion of individual CHCs in wounded and primed females (d) and males

921 (f) in relation to the median value of female or male naïve beetles as $\log _{2}$-fold change.

922 Clustering of CHCs is based on Euclidean distances. 